\title{
Os Fundamentos Científicos da Comunicação: Uma crítica flusseriana a comunicólogos brasileiros e seus desdobramentos epistemológicos ${ }^{1}$
}

\author{
The Scientific Foundations of Communication: \\ A critique to Flusserian communicologists from \\ Brazil and its epistemological developments
}

\begin{abstract}
Michael Hanke I michaelhankebeaga@yahoo.com.br Professor Adjunto da Universidade Federal do Rio Grande do Norte (UFRN), Natal, Centro de Ciências Humanas, Letras e Artes (CCHLA), no Departamento de Línguas e Literaturas Estrangeiras Modernas (DLLEM), e Professor Permanente do Programa de Pós-Graduação em Estudos da Mídia (PPgEM).
\end{abstract}

\section{Resumo}

Pouco, ou, se comparado com os períodos anterior e posterior, menos é sabido sobre a época francesa de Flusser. Uma de suas atividades, como comprovam documentos do Arquivo Flusser, foi a elaboração de pareceres sobre livros brasileiros, com a finalidade de julgar o mérito para tradução e publicação na França. Trata-se, pelo menos, de três livros analisados por Flusser: "A Comunicação do Grotesco", de Muniz Sodré, "Sociedade de massa (Comunicação e Literatura)", de Luiz Beltrão, e "Fundamentos Científicos da Comunicação", de vários autores cearenses. Os pareceres, com destaque ao último, e seus desdobramentos serão analisados em seguida. $\mathrm{O}$ artigo joga luz sobre um capítulo desconhecido da epistemologia e cientificidade da comunicação na década de 70a

\footnotetext{
Abstract

Little, or if compared with the periods before and after, less is known about the French time of Flusser. One of its activities, as evidenced by documents from the Flusser File, was the development of opinions about Brazilian books, in order to judge the merit for translation and publication in France. It is at least three books analyzed by Flusser: "The communication of the Grotesque," by Muniz Sodré, "Mass Society (Literature and Communication)" by Luiz Belträo, and "Scientific Foundations of Communication", several authors from Ceará. The opinions, especially the latter, and its consequences will be discussed below. The article clarifies an unknown chapter of epistemology and scientific communication in the 70.
} 


\author{
O "É pela grande força do presente \\ que deve ser interpretado o passado." \\ Friedrich Nietzsche ${ }^{2}$
}

\title{
Introdução
}

A biografia e a obra de Flusser, devido a uma série de pesquisas e publicaçóes, hoje é relativamente bem conhecida. Isso vale para a fase brasileira até 1972, assim como para a fase europeia, especificamente a fase dos trabalhos em alemão após 1978, mais ou menos. Menos conhecida são as atividades de Flusser entre essas datas, após sua chegada primeiramente na Itália, em Merano, em maio de 1972 e depois da mudança para a França em 1973, e 1978 (detalhes sobre as posições como professor visitante e demais atividades de publicação em Sander (1997, p. 11)).

Uma das atividades nas quais Flusser se empenhou foi a elaboração de pareceres de livros brasileiros sobre comunicação com a finalidade de averiguar o mérito para tradução e publicação na França. São pelo menos três, preservados no Arquivo Flusser, e eles tratam dos livros "A Comunicação do Grotesco", de Muniz Sodré, "Sociedade de massa (Comunicação e Literatura)", de Luiz Beltrão, e "Fundamentos Científicos da Comunicação", este último escrito por vários autores.

Esses pareceres são escritos em inglês e datam provavelmente de 1973. Isso porque o manuscrito do livro La force do Quotidien, publicado pela editora Maison Mame em 1973, foi escrito por Flusser em inglês e traduzido para o francês, sendo que Flusser, como afirma Klaus Sander, um dos melhores conhecedores do autor naquela época (que o acompanhou nas viagens na Alemanha), ainda se sentia inseguro na língua francesa (SANDER, 1997, p. 11) ${ }^{3}$. Já Le Monde codifié, de 1974 (depois publicado como artigo intitulado $O$ mundo codificado no livro homônimo em 2007 (FLUSSER, 2007)), é uma conferência ministrada em francês por Flusser, "Professeur de Communicologie à l'Université de São Paulo au Brésil” (1974, p. 3), em maio de 1973, e publicado em francês.

Os pareceres foram destinados e endereçados, obviamente, para a editora Maison Mame e sua série "Collection Medium", na qual publicou vários livros entre 1970 e 1972. Entretanto, segundo minhas informaçóes, a editora entrou em falência em 1975.

\section{Primeiros Desdobramentos}

Estas observaçóes permitem os seguintes primeiros desdobramentos:

1. A obra de Flusser é multilíngue. Além do português e do alemão, apresenta-se também inglês e francês. $\mathrm{O}$ acesso à obra passa por estes idiomas.

2. O caso mostra que não pode ser considerada confiável a chamada biblioteca de viagem de Flusser no Arquivo Flusser. Nenhum desses livros com pareceres realizados por Flusser aparece na lista publicada em Kommunikologie weiter denken (FLUSSER, 2009, p. 285-97). Conclusóes a partir dela devem ser feitas com muito cautela. 


\section{O livro Fundamentos Científicos da Comunicação}

O livro Fundamentos Científicos da Comunicação foi editado pela renomada Editora Vozes, em Petrópolis, na Coleção "Meios de Comunicação Social", série "Manuais", pelo conselho editorial de José Marques de Melo (São Paulo), Luiz Beltrão (Brasília) e Teresa Lúcia Halliday (Recife). A data da primeira edição é de 1973 e coincide com a produção do primeiro dos dois textos que compóem o livro Kommunikologie (1998), a Teoria de Comunicação de Flusser, ("Umbruch der menschlichen Beziehungen?”, escrito entre 1973 e 1974, e o segundo, Vorlesungen zur Kommunikologie/ Kommunikationstheorie Luminy, em 1977).

O livro é composto pela introdução e seis capítulos:

- Fundamentos Biológicos da Comunicação, de Expedito Teles,

- Fundamentos Antropológicos da Comunicação, de João Pompeu de Souza Brasil,

- Fundamentos Psicológicos da Comunicação, de José Maria Nascimento Pereira,

- Fundamentos Sociológicos da Comunicação, de E. Diatay Bezerra de Menezes,

- Fundamentos Lingüísticos da Comunicação, de Marcondes Rosa de Souza,

- Fundamentos Filosóficos da Comunicação, de Adísia Sá.

$\mathrm{Na}$ verdade, falar em comunicólogos não é completamente correto, porque somente Adísia Sá é professora-assistente do Departamento de Comunicação, porém, enquanto professora-adjunta, ela é da Faculdade de Filosofia do Ceará. O autor dos fundamentos biológicos da comunicação, Expedito Teles, é professor de Cosmologia e Fundamentos de Biologia da Faculdade de Filosofia do Ceará. O autor dos fundamentos antropológicos da comunicaçáo, João Pompeu de Souza Brasil, é professor de Antropologia, assistente na Faculdade de Ciências Sociais e Filosofia da UFC e titular na Escola de Serviço Social do Ceará. José Maria Nascimento Pereira, professor de Psicologia, Psicologia Médica e Psicologia Dinâmica (assistente na Faculdade de Medicina da UFC, titular na Escola de Serviço Social de Fortaleza e contratado pela Faculdade de Filosofia do Estado do Ceará). $\mathrm{O}$ autor dos fundamentos sociológicos da comunicação, Diatay Bezerra de Menezes, professor do Departamento de Sociologia da UFC e de Sociologia e Psicologia Social da Faculdade de Filosofia do Ceará. O autor dos fundamentos linguísticos da comunicação, Marcondes R. De Souza, professor de Comunicação em Língua Portuguesa do depto. de Letras Vernáculas da UFC e da Faculdade de Filosofia do Ceará. Levando em conta a procedência dos autores, podemos afirmar que nenhum deles é da área da comunicação. Entretanto, como publicam Fundamentos Científicos da Comunicação, deveriam ser, sim, considerados comunicólogos.

Como autores do livro, constam na capa "vários", enquanto na folha de rosto figura uma coordenadora, Adísia Sá (não uma organizadora). Porém, a introdução do livro não foi, como era de esperar, escrita por Adísia Sá, mas por Bezerra de Menezes. 
A obra nasceu, segundo Menezes, da iniciativa "da professora Adísia Sá, encarregada do ensino desta disciplina no Departamento de Comunicação Social da Faculdade de Ciências Sociais e Filosofia, da Universidade Federal do Ceará, e do apoio que lhe proporcionou o professor José Marques de Melo, da Universidade de São Paulo" (MENEZES, 1973, p. 9). Ela estava à frente $\mathrm{da}$ "tarefa derrotante [...] de desenvolver um programa de fundamentos científicos da comunicação [...] para os alunos do Curso de Comunicação Social”, uma "matéria tão vasta" que não pode ser resolvida por uma disciplina só, "mas sim por um conjunto delas" (MENEZES, 1973, p. 9). Mas ela não recuou e conseguiu, "de várias Escolas de Comunicação, o programa dessa 'disciplina', e ocorreu-lhe a ideia de coordenar um grupo polivalente e interdisciplinar que, de acordo com o plano previamente discutido, elaborasse um livro de texto para preencher as necessidades nesta área e facilitar o desempenho de inúmeros professores da matéria espalhados pelo país." (MENEZES, 1973, p. 9) A importância ou melhor necessidade de estudar a comunicação está, segundo Menezes, na onipresença dela:

... é a partir do momento em que o homem inicia a manipulação simbólica de seu ambiente e de si mesmo, é a partir do instante em que a linguagem e a comunicação - o que implica convivência social e intercâmbio cultural-permitem-lhe a criação de sistemas de açâo altamente complexos e variados, é a partir dai que o homem se torna verdadeiramente humano. (MENEZES, 1973, p. 10)

Menezes cita ainda "o criador da Cibernética", Norbert Wiener, segundo o qual a "linguagem é o maior interesse e a consecução mais característica do homem", responsável pelas conquistas do processo de hominização, cunhado pelas três características do raciocínio abstrato, ou seja, o pensamento hipotético-dedutivo, da "sua capacidade técnica, ou seja, a habilidade de confeccionar e usar instrumentos ou artefatos", e "a sua capacidade de comunicação através de símbolos, especialmente por meio da linguagem" (MENEZES, 1973, p. 10). Como na humanidade tudo parece girar em torno de sua sobrevivência e de sua convivência em grupos sociais, "todos os problemas científicos e tecnológicos, a saber, as questóes teóricas e pragmáticas com que nos defrontamos são a muitos respeitos problemas de comunicação" (MENEZES, 1973, p. 10), motivo pelo qual "o homem e a informação se colocam como pontos de referência cruciais” (MENEZES, 1973, p. 11). E nas sociedades contemporâneas cresce "o volume e a complexidade de informaçóes de toda ordem", produzindo, aspecto paradoxal, uma "explosão da ignorância" (MENEZES, 1973, p. 11). Enfim, a necessidade de estudar os fundamentos da comunicação se dá porque, "em última análise, todo conhecimento humano se converte em experiência transmissível (comunicação) e em saber aplicável (numa 'práxis')" (MENEZES, 1973, p. 11).

O livro se encontra, na opinião de Menezes, diante do problema de "que é praticamente impossível esgotar as dimensôes de um fenômeno tão amplo e complexo como a comunicação" (MENEZES, 1973, p. 11). Ele ainda lamenta que falte o capítulo sobre os fundamentos matemáticos da comunicação (não entregue pelo autor encarregado): “imperdoável' porque 'se trata de uma das dimensões mais fecundas na análise dos fenômenos 
comunicacionais" (MENEZES, 1973, p. 12). O estudo da produção, transmissão e recepção de sinais, da quantidade e da velocidade de informação, como iniciado por Wiener, Shannon e outros, demonstra que a importância da informação na teoria das comunicações tem "um papel análogo ao da entropia em Termodinâmica" (MENEZES, 1973, p. 12), capítulo que deveria ser integrado numa edição futura do livro "se houver ....". Referências de Menezes são, entre outros, Ross Ashby (An Introduction to Cybernetics, 1956), Norbert Wiener (Cybernetics, 1961), e F. Doria e Luiz Costa Lima (Dicionário Crítico de Comunicação, 1971).

O primeiro capítulo, "fundamentos biológicos da comunicação", de Expedito Teles, é resumido por Menezes desta forma: "a vida é organização e essa organização somente se realiza pela utilização e troca de informaçóes”, e "tal tipo de comunicação se dá no universo desde o nível micromolecular até as formas macroestruturais dos organismos vivos, fato que pode ser verificado pelo exame da evolução cósmica e biológica”. (1973, p. 12) O fato de que os processos vitais em geral repousam sobre uma rede de ações e reaçóes em que as noções de sinais, transmissão, informação e neguentropia têm um papel preponderante parece, segundo Menezes, ainda "mais evidente depois da decifração do código genético" (1973, p. 12, grifos do autor).

No capítulo "fundamentos antropológicos da comunicação", o autor João Pompeu de Souza Brasil, segundo Menezes, "defende [...] a ideia de que a cultura não está propriamente na concreção da atividade coletiva, isto é, nos seus produtos materiais, mas sim e sobretudo nas transformaçóes por que passa a mente humana (o que se confunde de certo modo com o crescimento e a complexificação do conhecimento) em consequência de sua ação criadora e vice-versa" (1973, p. 13). Isso se realiza "através de sistemas que permitam o intercâmbio de informaçóes entre os homens" que, na fala, tem "sua expressão mais refinada e abrangente [...] que fornece as categorias simbólicas para interpretação de outros mecanismos não falados para transmitir mensagens" (BRASIL apud MENEZES, 1973, p. 13).

No capítulo "Fundamentos psicológicos da comunicação", o autor José Maria Nascimento Pereira, segundo Menezes, enfoca "quase todos os fenômenos relevantes de natureza psíquica [...] em termos comunicacionais" (1973, p. 13), e apresenta um exame psicológico dos diversos componentes do processo comunicativo do homem, sendo "os símbolos, as mensagens, o emissor, o receptor, etc.” (1973, p. 13).

No capítulo "Fundamentos sociológicos da comunicação", escrito por ele mesmo, Menezes, com aproximação à perspectiva psicológica e antropológica, concebe a comunicação humana como "fato social e histórico que implica comunidade de experiências significativas” (1973, p. 13-14). Recorre a esquemas e paradigmas das ciências sociais "com vistas à explicitação do processo comunicativo", tentando "elaborar um modelo analítico dos tipos e níveis da comunicação social” (1973, p. 13). Lamenta náo poder ter a oportunidade de abordar as relaçôes entre processos de comunicaçáo e sistema social. 
No capítulo sobre os fundamentos linguísticos da comunicação, o autor Marcondes Rosa de Souza, segundo Menezes, destaca "o caráter de linearidade da comunicação por meio de signos lingüísticos, o que a particulariza em oposição a outras formas ou sistemas comunicacionais" (1973, p. 14). Vale a pena ressaltar que Menezes aponta um "equívoco fundamental", com conclusóes bastante discutíveis, no artigo em que ele quer deixar a juízo do leitor criticar.

O capítulo de Adísia Sá sobre os "Fundamentos filosóficos da comunicação" é marcado, segundo Menezes, por um estilo "frequentes vezes poético", e pode "como a própria autora observa", causar "estranheza num livro de fundamentos cientificos de comunicação um capítulo de especulação filosófica" (1973, p. 14).

Entretanto, na perspectiva de Adísia Sá, o homem é "um criador de valores" assim como de signos, e ao criar o signo, "dá a este signo um conceito e é em torno deste binômio signo/conceito que o homem vive, cria e se comunica”. Tal visão é coincidente com a opinião defendida por Ernst Cassirer no seu ensaio An Essay on Man (1944), "no qual ele propóe o símbolo como chave da natureza humana" (MENEZES, 1973, p. 15). No "universo simbólico" do homem, a linguagem, o mito, a arte, a religião etc. compóem os fios que tecem essa rede simbólica o que, em vez de um animal racional, deixa Cassirer definir o homem como animal simbólico. E isso é uma das afirmaçôes mais citadas por Flusser com referência a um autor, que é Ernst Cassirer.

Esses trechos foram apresentados em detalhes porque eles estão de acordo com Flusser.

\section{O parecer de Flusser}

O resultado do parecer de Flusser sobre o livro em questáo é negativo: ele desaconselha a tradução e publicação em francês. O que nos interessa são os motivos. Flusser inicia seu parecer com as palavras: "This book seems to be a joint undertaking by teachers at the University of Fortaleza, Ceará, and the purpose is far more pretentious, although less disciplined, than the title 'Scientific Foundations of Communication' implies." (p. 1) Em português: "Este livro parece ser um empreendimento conjunto de professores da Universidade de Fortaleza, Ceará, e o propósito é muito mais pretensioso, embora muito menos disciplinado que o título de 'Fundamentos Científicos da Comunicaçáo' implica." (p. 1)

Pretensioso demais porque as várias partes não querem apresentar o problema da comunicaçáo, mas praticamente da ciência na íntegra. E menos disciplinado, porque:

o que o livro oferece não pode ser estritamente chamado de uma abordagem "científica" para os problemas de comunicaçäo, mas uma abordagem bastante circunstancial para essa (a comunicação) a partir de vários campos do conhecimento. A impressão é de que o livro recebeu um nome errado. Ele deveria ser intitulado como "Comunicação sob o olhar de professores de disciplinas que são mais ou menos relacionados a ela". Em consequência, surge a impressäo de que cada colaborador do livro quer expor, com maior ou menor sucesso, sua própria disciplina e tenta forçar alguma relação entre esta 
e o problema da comunicação. Tal tentativa deliberada para forçar a comunicação em um contexto onde ela náo pertence é uma lacuna muito maior do livro do que a falta de um capitulo dedicado à teoria da informação, admitido no prefácio. Isto será visto mais claramente depois de tratar cada capitulo.

E para justificar essa conclusão, Flusser discute cada contribuição separadamente.

Segundo Flusser, a primeira delas, sobre os "Fundamentos biológicos da comunicação", trata a bioquímica da célula viva, e não tem nada a ver com o título anunciado, ou seja, não há nenhuma menção dos aspectos biológicos da comunicação ("por exemplo, o efeito da TV na visão, o efeito da música em audição e assim por diante"), nem da biologia no sentido tradicional do termo (morfologia, fisiologia, comportamento etc.).

Não se pode escapar da impressão de que o autor não sabe o que a "comunicação" significa, mas também de que ele não está escrevendo sobre a biologia, mas sobre um aspecto especifico da mesma que não está relacionada à comunicação, no sentido usual do termo (p. 1).

O autor nem aproveita tematizar a fraca relação entre o código genético e códigos num sentido geral e assim Flusser conclui: "O capítulo é interessante para o leigo em bioquímica celular, mas não tem lugar em um livro sobre comunicação." (p. 1)

O segundo capítulo sobre Fundamentos antropológicos da comunicação, Flusser considera igualmente surpreendente.

Nenhuma discussão sobre os aspectos antropológicos da comunicação que o leitor poderia esperar é oferecida. Não há consideração, por exemplo, do efeito antropológico dos meios de comunicação, nem os meios de comunicação em culturas primitivas são discutidos, nenhuma teoria comparativa da comunicação é tentada. (p. 1)

Em vez disso, o autor apresentaria um esboço da origem da espécie humana e uma comparação anatômica entre homem e primatas. Enfim, resume Flusser: "Este autor, também, não parece saber o que 'comunicação' significa" (p. 1).

Continuando, Flusser considera o terceiro capítulo, "Fundamentos psicológicos da comunicaçáo", "o mais ingênuo de todos" (p. 2). Apresenta conceitos psicológicos bastante nebulosos e "recomendaçôes para o bom uso da comunicação", mas nem chega perto dos problemas psicológicos da comunicação tais como "alienação, condicionamento, informação consciente e subliminar etc.", até nem imagina a existência deles, e "parece desconhecer completamente toda a problemática da comunicação, embora ele pareça ter apanhado alguns termos na imprensa diária que têm a ver com isso." (p. 2)

O quarto capítulo sobre os Fundamentos sociológicos da comunicação "é de longe o melhor. É uma pena não ter sido concluído, (como o autor confessa), e incluído neste livro, ao invés de ter sido publicado separadamente. O ensaio dá uma perspectiva muito densa e inteligente sobre as estruturas sociais de comunicação" (p. 2). 
O quinto, "Fundamentos linguísticos da comunicação", não trata esse tema anunciado, mas discute alguns aspectos da linguística e da teoria da crítica literária, e, em respeito a esses assuntos, é de algum interesse, mas evita problemas fundamentais "como linearidade, diacronicidade da linguagem etc.” (p. 2).

O sexto capítulo sobre fundamentos filosóficos da comunicação, na opinião de Flusser, nem merece um resumo.

Depois dessa crítica escrupuloso e criteriosa de cada capítulo, Flusser sintetiza o parecer e acrescenta um aspecto cultural:

The book illustrates clearly the cultural situation of a university in the Brazilian north-east: a place almost entirely "without communication" with the concrete problems in the advanced centers, but with an enthusiastic drive to keep "up to date" with these problems. It is very characteristic that no chapter for the "foundations of communication by theory of communication" is included, and that its lack is not even felt. There can be no better demonstration for the tragedy of underdeveloped alienation. (p. 2)

Em português:

O livro ilustra claramente a situação cultural de uma universidade no nordeste brasileiro: um lugar quase que totalmente "sem comunicação" com os problemas concretos dos centros avançados, mas com uma vontade entusiasmada para se manter "atualizado" com esses problemas. É muito característico que nenhum capitulo dos "fundamentos da comunicação pela teoria da comunicação" esteja incluido, e que sua falta não seja mesmo sentida. Não pode haver melhor demonstração para a tragédia de alienação subdesenvolvida. (p. 2)

Vale lembrar que Flusser não tem ressentimentos contra o nordeste, e sempre se manifestou contra a desigualdade social e regional no Brasil, apontando a situação do nordeste como injustiça social. No capítulo "Miséria", de "Fenomenologia do Brasileiro", apresenta três formas desta das quais a segunda é a "miséria da família nordestina em São Paulo" (FLUSSER, 1998, p. 121). E a construção da nova capital Brasília tem, segundo Flusser, entre várias funçôes, a de integrar o nordeste subdesenvolvido e sofrido num processo econômico, social e cultural (FLUSSER, 1994, p. 272) ${ }^{4}$. E de forma irônica, em outro artigo intitulado "Sabonetes", critica a desigualdade entre os vários mundos, Primeiro, Segundo, Terceiro e Quarto Mundo (FLUSSER, 1998, p. 149-152).

Entretanto, para Flusser a falta de teoria de comunicação num livro sobre fundamentos científicos da comunicação é um sinal de falta de desenvolvimento, o que mostra a importância que Flusser dá a essa questão e como ele tinha uma ideia clara e bem conceituada dessa área (articulada em vários trabalhos, como O que é comunicação (2007), On the theory of Communication (2002), Kommunikologie (1998) e Kommunikologie weiter denken (2009)). 
O parecer é finalizado com uma recomendação:

Do jeito como está, na minha opinião, o livro não deveria ser publicado na França. Mas o capitulo sobre "Fundamentos Sociológicos da Comunicação", de E. Diatay Bezerra de Menezes merece, creio eu, ser incluido na sua série "Collection Medium". (p. 2)

\section{Os outros pareceres}

1. Muniz Sodré: "A Comunicação do Grotesco"

O parecer sobre o livro de Muniz Sodré é bastante favorável. De início, Flusser apresenta brevemente o conteúdo. Sodré defende, segundo Flusser, que no Brasil "os mass media têm um propósito mais ou menos consciente e deliberado, ou seja, abordar uma cultura de massa que é alienada da situação real social, econômica e política (mesmo o cultural)" - ("mass media have a more or less conscious and deliberate purpose, namely to bring about a mass culture which is alienated from the social, economic and political, (even the cultural), real situation." (p. 1). Este procedimento dos Meios de massa (mass media) é baseado em dois métodos. O primeiro é "mostrar virtualidades específicas inerentes à situação real [do Brasil] como se fossem reais". O segundo apresenta aqueles fenômenos que não podem ser mascarados como exceçóes grotescas ("the mass midia [...] show [...] some aspects of the real situation [...] too obvious to be totally hidden [...] as if they were grotesque exceptions."). Flusser considera essa tese como muito interessante e provavelmente correta ("this very interesting, and probably correct, thesis") e trata ainda das quatro seçôes que Sodré apresenta em seguida. Chega finalmente à conclusão de que o ensaio, apesar de ser muito bom, entretanto, não serviria para leitores europeus. Não só pressupóe bastante conhecimento sobre o Brasil para acompanhar os argumentos, mas também porque o livro foi escrito com muita cautela para driblar a censura. Por isso, desaconselha a publicação na França.

O ensaio é muito bom, mas talvez não seja adequado para os leitores europeus. Não só porque pressupóe conhecimento sobre o Brasil, mas também porque está escrito com muita cautela para evitar a censura brasileira. Eu não acredito que possa ser publicado na França em sua forma atual. (p. 1)

2. Luiz Beltrão: "Sociedade de massa (Comunicação e Literatura)"

O parecer sobre o livro de Luiz Beltrão: "Sociedade de massa (Comunicação e Literatura)" é menos favorável, para não dizer destruidor. Diante da posição de Luiz Beltrão como "pioneiro dos estudos científicos sobre comunicação no Brasil" (MARQUES DE MELO, sem data, p.7), da qual Flusser sem dúvida estava ciente, ele pede sigilo de seu parecer ("PS: I beg you to keep this critique in secret.").

Segundo Flusser, Beltrão, na primeira parte do livro, defende três fases da sociedade: tradicional, plural e de massa, porém, ele critica o fato de Beltrão citar muitos autores e todos extensivamente, e observa que "nenhuma informação nova (ou mesmo interessante) é dada". Parece um manual de aula, talvez 
interessante por motivo didático, mas sem nada contribuir para as discussões atuais sobre os problemas da sociedade de massa. Em relaçáo à segunda parte, o desafio dos mass media para escritores, Flusser acredita que o autor não refletiu sobre os problemas suficientemente. Cheio de citaçóes, o autor não chegaria a tocar nos problemas de verdade numa sociedade de massa, como a liberdade, a manipulação da mídia, da alienação, da censura, etc. Essa parte também aparenta ser um manual para aulas. Resultado:

O livro deixa uma impressão dolorosa. Porque representa uma enumeração de uma grande quantidade de informaçôes, mais ou menos desconectada, não se pode escapar da impressão de que o autor quer mostrar a sua "cultura", sem contribuir em nada para um problema que é tão importante no momento e, na situação brasileira, tem tantos especificos e dolorosos aspectos. Em suma: o livro parece ser um produto de uma mentalidade que, torcemos, deveria ser superada pela cultura brasileira. Uma mentalidade "subdesenvolvida" por causa de grandes declaraçôes sem mensagens verdadeiras. Eu não acho que ele deve ser publicado (a não ser como um exemplo de "alienação subdesenvolvida").

PS: Pesco-lhe para manter esta crítica em segredo. (p. 1)

\section{Segundos Desdobramentos}

1. Flusser foi, com toda razão, criticado por não citar referências nas obras dele. Assim, é sempre difícil reconstruir as influências e fontes. Os pareceres, entretanto, mostram Flusser como leitor crítico e criterioso. A leitura não é superficial, mas profunda, e os argumentos críticos bem elaborados e justificados. Além dos livros com pareceres, considera o interesse do público francês. A postura de Flusser é a de um leitor-resenhista competente e responsável, que não faz pareceres "levianos" (favoráveis, sem senso crítico). Esse leitor é diferente do Flusser autodidata da década de 50 e 60, que faz leituras idiossincráticas (de Heidegger, por exemplo). É um leitor à altura do assunto.

2. Com Muniz Sodré, Luiz Beltrão e, indiretamente, José Marques de Melo, três representantes significativos da área da comunicação brasileira dessa época, Flusser, apesar da sua saída do Brasil, tinha conhecimento e mais familiaridade com esta área do que imaginado.

3. Se o livro Fundamentos Científicos da Comunicação é tão fraco como Flusser defende, não podemos dispensar o editor da série, José Marques de Melo, da responsabilidade de tê-lo publicado.

4. Em termos de pesquisadores, temos uma rejeição do trabalho científico abordado de Luiz Beltrão e José Marques de Melo e uma aceitação daquele de Muniz Sodré.

5. O autor desses pareceres toma a teoria da comunicação como ponto de partida e referência acadêmica (e não, por exemplo, a filosofia). Isso não surpreende, porque Flusser estava prestes a escrever sua obra 
principal, a teoria da comunicação (Kommunikologie, ainda não traduzido para o português). Flusser tinha, como escreve no seu autorretrato "Em busca de significado", de 1969, descoberto a teoria da comunicação em 1965 e depois observa que ela, nos tempos atuais, tomou o papel da filosofia como carro-chefe das Humanidades, o que é verificado pelos pareceres. Eles mostram um comunicólogo que sabe muito bem defender a sua área. Mesmo em fluxo, Flusser tinha uma posição firme.

\section{Referências Bibliográficas}

BACHELARD, Gaston. Epistemologia. Trechos escolhidos por Dominique Lecourt. Rio de Janeiro: Zahar editores, 1977.

FLUSSER, Vilém. Muniz Sodré: A Comunicação do Grotesco. Manuscrito não publicado, Arquivo Flusser, inglês, sem data, 1 página.

Luiz Beltrão. Sociedade de massa (Comunicação e Literatura). Manuscrito não publicado, Arquivo Flusser, inglês, sem data, 1 página.

- Vários: Fundamentos científicos da comunicação. Manuscrito não publicado, Arquivo Flusser, inglês, sem data, 2 páginas.

. La Force do Quotidien. Paris: Maison Mame, 1973.

. Le Monde codifié. Paris, Institut de l'Environnement, 1974.

. Brasilia oder Die Stadt welcher Zukunft? [1970] In: Brasilien oder die Suche nach dem neuen Menschen. Für eine Phänomenologie der Unterentwicklung. Mannheim: Bollmann 1994, p. 171-276.

____. Kommunikologie. Frankfurt am MaIn: Fischer, 1998.

. Fenomenologia do Brasileiro. Em Busca de um Novo Homem.

BERNARDO, Gustavo (Org.). Rio de Janeiro: EdUERJ, 1998.

. Sabonetes. In: Ficçóes Filosóficas. São Paulo: Edusp, 1998, p. 149-152.

. On the Theory of Communication. In: Writings, 2002a, p. 8-20.

. In: Search of Meaning. In: Writings, 2002b, p. 197-208.

. O que é Comunicação? In: O mundo codificado. Por uma filosofia do design e da comunição. São Paulo: Cosac Naify, 2007, p. 88-100.

. O mundo codificado. Por uma filosofia do design e da comunição. Sáo Paulo: Cosac Naify, 2007.

Kommunikologie weiter denken. Die Bochumer Vorlesungen. Herausgegeben von Silvia Wagnermaier und Siegfried Zielinski. Mit einem Vorwort von Friedrich A.Kittler und einem Nachwort von Silvia Wagnermaier. Frankfurt am MaIn: Fischer, 2009.

MARQUES DE MELO, José. Luiz Beltrão: pioneiro dos estudos de Folkcomunicação no Brasil. 19??, p. 1-8. Disponível em: <http://www2.metodista.br/unesco/luizbeltrao/premio.jurados.htm>. Acesso em: 28 mai. 2012. 
MENEZES, E. Diatay Bezerra de. Introdução. In: Fundamentos Científicos da Comunicação. Petrópolis: Editora Vozes, 1973, p. 7-15.

SÁ, Adísia (Coordenadora), E. Diatay Bezerra de Menezes, Expedito Teles, José Maria Nascimento Pereira, João Pompeu de Souza Brasil e Marcondes Rosa de Souza: Fundamentos Científicos da Comunicação. (Coleção "Meios de Comunicação Social" 8, Série Manuais/5). Petrópolis: Editora Vozes, 1973.

SANDER, Klaus. Biographie. In: Siemens Medienkunstpreis 97. Herausgegegeben vom Siemens Kulturprogramm München: Selbstverlag ZKM Karlsruhe, 1997, p. 11-12.

\section{Notas}

1. Trabalho apresentado no Simpósio "Flusser em Fluxo", realizado em 24 e 25 de maio 2012 na Universidade Federal de Ceará (UFC) em Fortaleza, sob o título "Os Fundamentos Científicos da Comunicação. Uma crítica flusseriana a comunicólogos cearenses e seus desdobramentos", a ser publicado nos anais do congresso.

2. Unzeitgemässe Betrachtungen. Zweites Stück: Vom Nutzen und Nachtheil der Historie für das Leben. Tradução português apud Bachelard (1977, p. 182).

3. Apesar de ter morado na França, o contato de Flusser com a cultura francesa foi fraco, mais fraco que com outros (alemão, tcheco, judeu, brasileiro). Ele admite que "My lack of contact with French civilization is one of my most serious shortcomings." (2002b, p. 201).

4. Em alemão: "Man schlage diese Adern [Brasílias] in Richtung des dicht bevölkerten, hungernden und durstenden Nordostens, um die unterentwickelten Massen in den wirtschaftlichen, sozialen und kulturellen Prozess hineinzuziehen." (1994, p. 272) - Em português: "[É um projeto de] estender estas veias [de Brasília] na direção do densamente povoado Nordeste, faminto e com sede, para integrar as massas subdesenvolvidas no processo econômico, social e cultural." (Tradução do autor). 


\section{Anexo I:}

\section{VILÉM FLUSSER}

Vários: Fundamentos científicos da comunicação.

This book seems to be a joint undertaking by teachers at the University of Fortaleza, Ceará, and the purpose is far more pretentious, although far less disciplined, than the title "Scientific foundations of communication" implies. It is far more pretentious in the following sense: its various parts pretend not only to give to the reader a general outlook on the problem of communication, but on practically the whole field of science. It is far less disciplined in the following sense: what the book offers cannot be strictly called a "scientific" approach to the problems of communication, but a rather circumstantial approach to it from various fields of knowledge. The impression is that the book was misnamed. It should be called something like "Communication as seen by teachers of disciplines that are more or less related to it". In consequence, one has the feeling that each contributor to the book is exposing, more or less successfully, his own discipline, and tries to force some relation between it and the problem of communication. Such deliberate attempt to force communication into a context where it does not belong is a far greater shortcoming of the book than the lack of a chapter dedicated to theory of information, admitted in the preface. This will be seen more clearly, if each chapter is considered.

The first chapter, "biological foundations of communication" is in fact an enormously wide and superficial sketch of a cosmogony, and some rather detailed consideration of the biochemistry of the living cell. It has therefore almost nothing to do with its title. Not only is there no mention at all of the biological aspects of communication, (for instance: the effect of TV on vision, the effect of music on audition and so forth), but not even of biology in the common sense of the term, (plant and animal morphology, physiology, behavior and so forth). One cannot escape the feeling that the author does not know what "communication" means, but also, that he is not writing about biology, but about one specific aspect of it which is unrelated to communication in the usual sense of the term. (Unless we should consider his discussion of the genetic code as obliquely related to codes in general, but the author does not help much even in this aspect.) The chapter is interesting for the layman in cell biochemistry, but has no place in a book on communication.

The second chapter, "anthropological foundations of communication", is equally surprising. No discussion of anthropological aspects of communication which the reader would expect is offered. There is no consideration of for instance the anthropological effect of mass media, no media in primitive cultures are discussed, no comparative theory of communication is attempted. Instead, a short sketch of the origin of the human species is given, and an anatomical comparison between man and apes is offered, apparently to show that apes are anatomically uncapable of speech. This author, too, does not seem to know what "communication" means. 


\section{$-2-$}

The third chapter, "psychological foundations of communication", is the most naive of all. It gives some rather nebulous psychological concepts, and a sort of "recommendations for the good use of communication". The author does not touch the problem of psychological aspects of communication at all, (alienation, conditioning, conscious and subliminar information and so forth), but he does not even suspect that such problems exist. He seems to be completely unaware of the whole problematic of communication, although he seems to have caught some terms in the daily press that have to do with it.

The fourth chapter, "sociological foundations of communication", is by far the best one. One feels sorry for it not have been concluded, (as the author confesses), and for it to have been included in this book, instead of having been published separately. The essay gives a very dense and intelligent outlook on the social structures of communication.

The fifth chapter, "linguistic foundations of communication", is not at all what she title suggests, but a discussion of some aspects of linguistics and theory of literary criticism. It has some interest, as far as this goes, but the fundamental problems, (like linearity, diachronicity of language and so forth), are not mentioned.

The sixth chapter, "philosophical foundations of communication", is not even worth of a résumé, (in my opinion).

The book illustrates clearly the cultural situation of a university in the Brazilian north-east: a place almost entirely "without communication" with the concrete problems in the advanced centers, but with an enthusiastic drive to keep "up to date" with these problems. It is very characteristic that no chapter for the "foundations of communication by theory of communication" is included, and that its lack is not even felt. There can be no better demonstration for the tragedy of underdeveloped alienation.

As it is, the book should not be published in France in my opinion. But the chapter on "sociological foundations of communication" by E. Diatay Bezerra de Menezes merits, I believe, to be included in your series "Collection Medium". 


\section{Anexo II}

\section{VILÉM FLUSSER}

\section{Muniz Sodré: "A Comunicação do Grotesco".}

This is an essay which defends a thesis. The thesis may be stated as follows: In Brazil, mass media have a more or less conscious and deliberate purpose, namely to bring about a mass culture which is alienated from the social, economic and political, (even the cultural), real situation. This purpose is achieved by two distinct, but complementary methods. The first method consists of showing specific virtualities inherent in the real situation as if they were real. (For instance: The economic possibilities of the Amazon basin are shown as if they were being already put at the disposal of the nation). This method allows the covering-up of the real situation, which goes on almost unperceived by the participant in mass culture. But nonetheless, of course, some aspects of the real situation are too obvious to be totally hidden. In order to prevent the "mass man" to see them, the mass media apply a second method. They show those inevitable aspects of reality not as they are, (namely characteristic for the situation), but as if they were grotesque exceptions. (For instance: the shanty-town inhabitant of Rio de Janeiro, ("favelado"), is shown not as a typical inhabitant of Rio, but as a somewhat exotic and ridiculous figure). This method allows the media to make the "mass man" believe that what is in reality characteristic of the Brazilian situation is only a grotesque exception. Thus the media prevent an identification of the "mass man" with his situation.

To prove this very interesting, and probably correct, thesis, the essay is divided into various sections. In the first section an attempt is made to justify the method of the theory of communication to analyse any given cultural situation. In the second section the distinction between various culture structures is attempted. The most important distinction is between élite and mass culture, and between popular and mass culture. (In this section the author shows how Brazilian mass culture takes advantage of, (and disfigures), Brazilian popular culture). In the third section the thesis is demonstrated for Brazilian illustrated magazines. In the fourth section the thesis is illustrated in various TV programs. The argument is very convincing for one who knows well the Brazilian mass media, but for one who is ignorant of them it is difficult to follow the argument in its details. Throughout the author shows the enormous influence of the United States on Brazilian mass media, and therefore on Brazilian mass culture. A parallel between the media in America and Europe on one hand, and Brazil on the other, is always given.

The essay is very good, but possibly not suited for European readers. Not only, because it presupposes knowledge of Brazil, but also because it is written very cautiously to avoid Brazilian censorship. I do not believe that it can be published in France in its present form. 


\section{Anexo III:}

\section{VILÉM FLUSSER}

Luiz Beltrão: "Sociedade de massa (Comunicação e Literatura)"

This book consists of two rather independent parts. The first one is an attempt to define mass society. The second part is an attempt to define the position of the writer, (and the intellectual in general), with regard to mass media. In the first part three stages of social structures are presented: the "traditional" society, the "pluralistic" society, and the "mass" society. Many authors are cited, long quotations are presented, but no original, (or even interesting), information is given. One has the impression that this part of the book is a sort of resumé of a course given by the author at the University of Brasilia. It may have some didactic interest, but it contributes nothing, (in my opinion), to present discussions concerning mass society problems.

The second part tries to point out the choice and the challenge presented by the mass media to writers. I do not believe that the author has thought sufficiently about the problems. This part, too, is full of quotations, and one has the impression of a show of the author's erudition. The true problems of freedom in a mass society, of manipulation of the media, of the alienating effect of media, of censorship in the media, and so forth, are either discussed very superficially, or else shown under a point of view which to me seems to be mistaken. This part, too, is a sort of sketch for lectures.

The book leaves a painful impression. Because it represents the enumeration of a great amount of rather disconnected information, one cannot escape the feeling that the author wants to show off his "culture", without contributing anything important to a problem which is so very important at present, and has so many specific, (and painful), aspects in the Brazilian situation. In short: the book seems to be a product of a mentality one should hope to be surpassed by Brazilian culture. An "underdeveloped" mentality, given to large statements without true messages. I do not think it should be published, (unless as an example of "underdeveloped alienation”).

PS: I beg you to keep this critique in secret. 